\title{
MODELLING DUNE EROSION, OVERWASH AND INUNDATION OF BARRIER ISLANDS
}

\author{
Bas Hoonhout ${ }^{1}$ and Jaap van Thiel de $\operatorname{Vries}^{1,2}$
}

\begin{abstract}
Physical model experiments are performed at Deltares to investigate the morphological response of barrier islands on extreme storm events. The experiments included dune erosion, overwash and inundation regimes. Extensive measurement techniques made detailed comparison with numerical models possible. This paper describes the comparison between the physical model results and the numerical morphodynamic model XBeach. It appeared that XBeach simulates the main characteristics in hydro- and morphodynamics at profiles with shallow foreshores, which are characteristic for barrier islands, well. However, the absolute results of especially the overwash experiments still do not agree with the measurements. It is expected that several generic issues regarding small-scale physical model experiments are of influence here. Nevertheless, calibration of the XBeach model seems to be necessary for shallow profiles. Especially the calibration of the wave characteristics on the shallow foreshore, related to the morphodynamics is far from trivial.
\end{abstract}

Keywords: dune erosion, physical modeling, barrier islands, erosion, overwash, inundation

\section{INTRODUCTION}

$10 \%$ of the world's coastline consists of barrier coasts. These areas are often characterized by a highly dynamic behavior, which makes them very susceptible for changes in the environment. Prediction of the response of these barrier coasts to storms is therefore complicated, but important, since the population in coastal areas is rising steadily and changes in environment cannot be averted.

The behavior of barrier islands depends on their environment. Barrier islands along the United States coastline are frequently overwashed and inundated in the hurricane season. The islands function as a protection for the areas behind these barriers. In contrast, in the Netherlands populated barrier islands are present where overwash is not often seen, but erosional processes are characterized by the relatively gentle slopes in the bathymetry.

This paper presents the numerical modelling of barrier islands using the process-based morphological model XBeach. The results are compared to the results of physical model tests performed at Deltares, formerly known as WL|Delft Hydraulics (Figure 1).

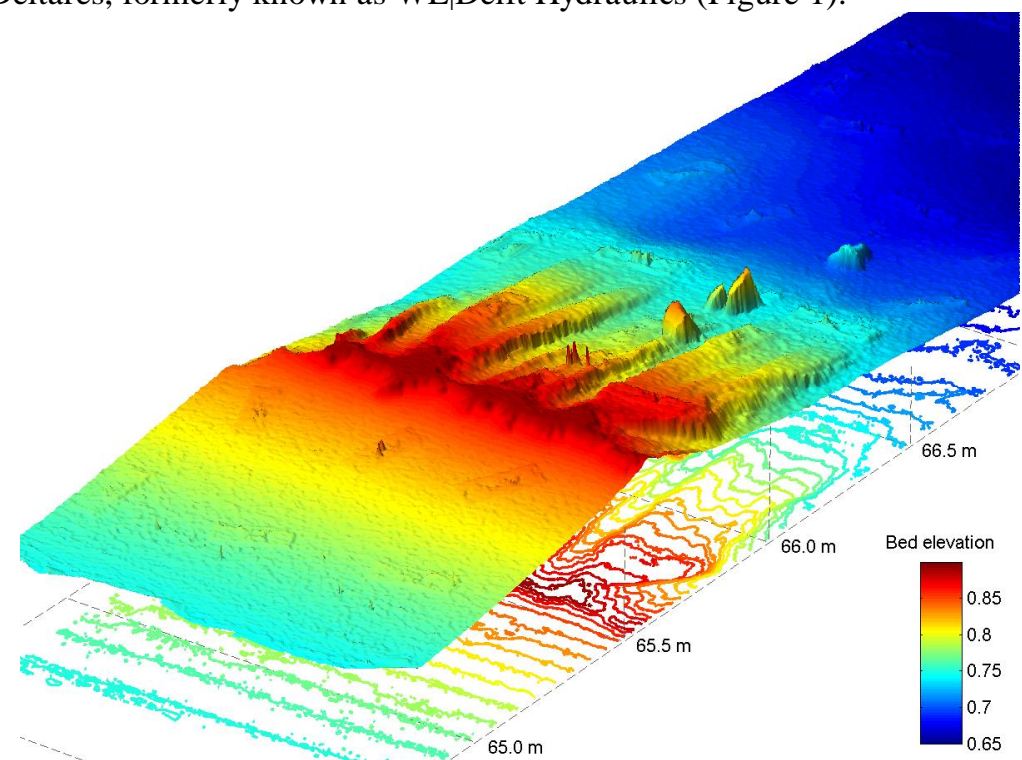

Figure 1. 3D imagery obtained from physical flume experiments

\section{PHYSICAL MODEL EXPERIMENTS}

Validation of overwash models is often difficult due to a lack of measurement data. A series of experiments in the Scheldt Flume of Deltares was initiated to provide a dataset for validation

\footnotetext{
${ }^{1}$ Hydraulic Engineering, Deltares, P.O.Box 177, 2600MH Delft, The Netherlands. E-mail: bas.hoonhout@deltares.nl

${ }^{2}$ Coastal Engineering, Civil Engineering and Geosciences, Delft University of Technology, Stevinweg 1, P.O.Box 5048, 2600GA Delft, The Netherlands.
} 
[Deltares, 2011]. Moreover, the dataset describes dune erosion with gently sloped beaches. The experiments involve a series of two-dimensional erosion tests in the Scheldt Flume, which is a $100 \mathrm{~m}$ long flume with a depth of $1.2 \mathrm{~m}$ and a width of $1 \mathrm{~m}$. Schematized dune profiles characteristic for the barrier islands found in The Netherlands and along the United States coast are used (Figure 2). The experiments are subdivided in different stages that slightly correspond to the impact regimes described by [Sallenger, 2000]. Experiments are started of with a collision regime characteristic for the barrier islands found along the Dutch coast. Subsequently, the conditions are altered to investigate hurricane impacts characteristic for barrier islands along the coast of the United States.

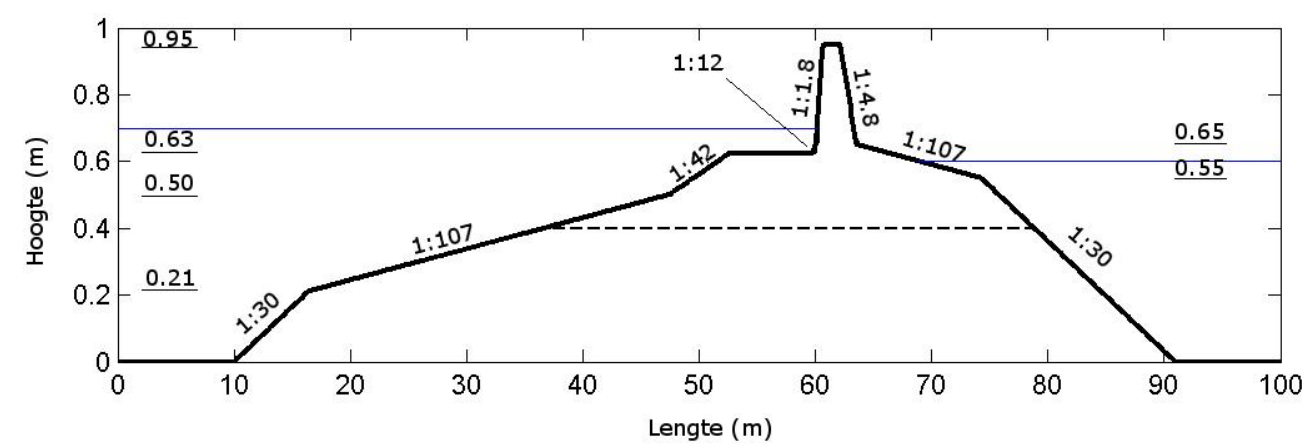

Figure 2 Schematized profile used in physical model experiments

The profile development is not only measured using an automated wheel-profiler, but also using $3 \mathrm{D}$ imagery that provides detailed information of especially the morphological processes at the rearside slope of the barrier (Figure 1). Hydrodynamics are measured using wave height and flow velocity meters, but also using layer thickness meters that are capable of measuring multiple layers: water level and bathymetry level. In order to measure the large flow velocities at the rear-side slope of the barrier and to be able to correlate these to the morphological behavior obtained from the 3D imagery, the rear-side slope is also monitored using Particle Image Velocimetry (PIV, Figure 3).

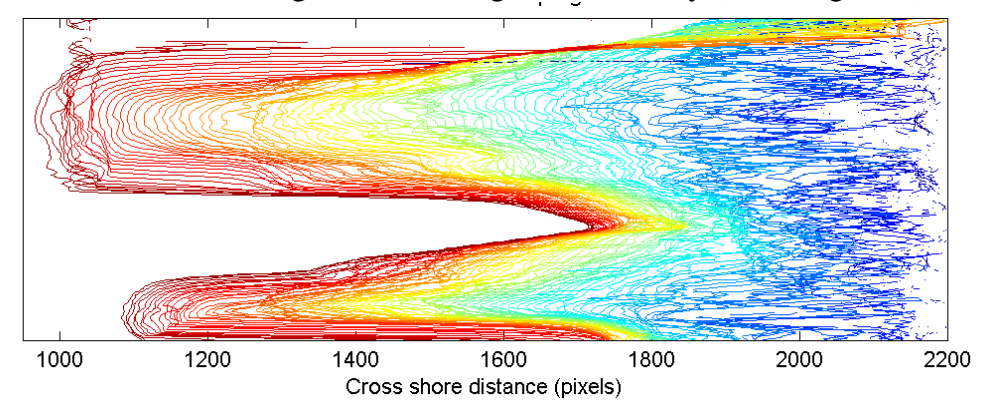

Figure 3 Plan view of bore progression on rear-side slope of barrier

The physical model experiments performed and relevant for the numerical model experiments are summarized in Table 1. Each erosion experiment is succeeded by an overwash experiment using the final profile of the erosion experiment. In order to force the overwash to occur, the water level, the wave height or the wave period is increased. In case increasing the wave parameters appeared not to be sufficient, the water level is increased as well.

All experiments are performed with a depth scale of 40 and a horizontal contraction of 1.65 . The scale relations derived by [Vellinga, 1986] are used to adapt time and sediment diameters accordingly. The sediment used had a D50 of about $100 \mu \mathrm{m}$. 


\begin{tabular}{|l|l|l|l|l|}
\hline \multicolumn{5}{|c|}{ Table 1 Measurement programme } \\
\hline Experiment & Purpose & WL & $\mathrm{H}_{\mathrm{m} 0}$ & $\mathrm{~T}_{\mathrm{p}}$ \\
\hline & & {$[\mathrm{m}]$} & {$[\mathrm{m}]$} & {$[\mathrm{s}]$} \\
\hline A2a & Erosion & 0.70 & 0.225 & 2.25 \\
\hline A2d & Overwash & $0.72-0.75$ & 0.225 & 2.25 \\
\hline B1a & Erosion & 0.70 & 0.300 & 2.25 \\
\hline B1d & Overwash & $0.70-0.74$ & 0.300 & $2.25-3.00$ \\
\hline B2a & Erosion & 0.70 & 0.225 & 3.00 \\
\hline B2d & Overwash & $0.70-0.74$ & $0.225-0.300$ & 3.00 \\
\hline C1a & Reference & 0.70 & 0.225 & 2.25 \\
\hline
\end{tabular}

For the calibration of the numerical model, a reference experiment is used (C1a). The reference experiment is performed using a reference profile, characteristic for the coast of Holland, The Netherlands. The profile is similar to the profile used in the other experiments, but it lacks the long, shallow foreshore (Figure 4). In fact, a second dune is placed at the seaward side of the foreshore, resulting in a double dune system of which only the first dune is tested in experiment C1a. The advantage of the reference profile is that XBeach is proven to perform well on this profile [Van Thiel de Vries, 2009]. It is therefore possible to use all experiments with a shallow foreshore for verification and isolate the characteristics in both the physical and numerical experiments related to the shallow foreshore.

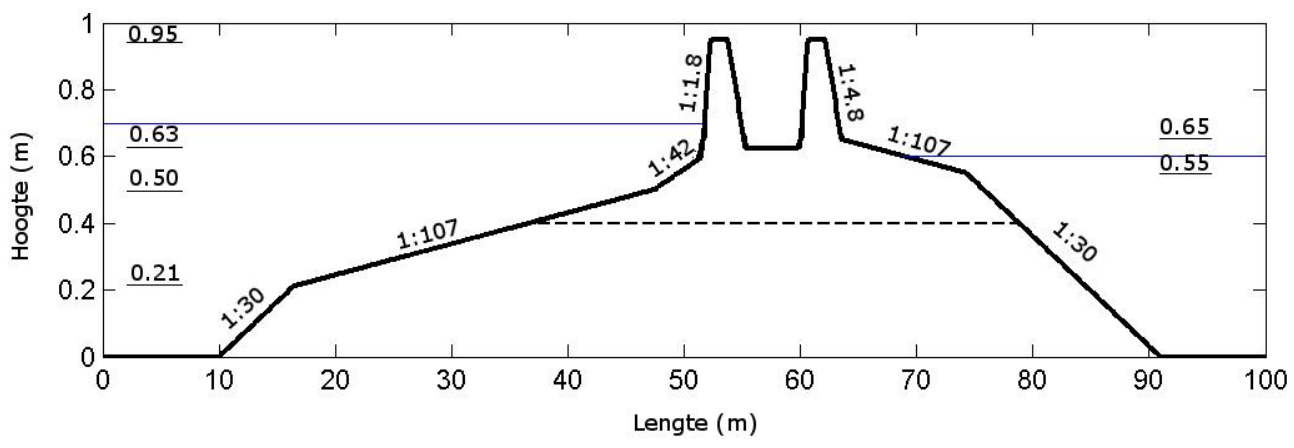

Figure 4 Schematized profile used as reference for the physical model experiments (C1a)

\section{PHYSICAL MODEL RESULTS}

It appears from the physical model results that the hydrodynamics on the gently sloped profiles, that are characteristic for barrier islands, are dominated by low-frequency waves. As hypothesized, most high-frequency waves dissipate on the shallow areas distant from the dune toe. High-frequency wave energy is partly shifted towards the low-frequency areas of the wave spectrum, increasing the low-frequency wave energy both relatively as absolutely (Figure 5). Moreover, the overwash and inundation of the barrier islands can be related to the low-frequency wave periods as well, making the entire subject low-frequency dominated [McCall et al., 2011]. 

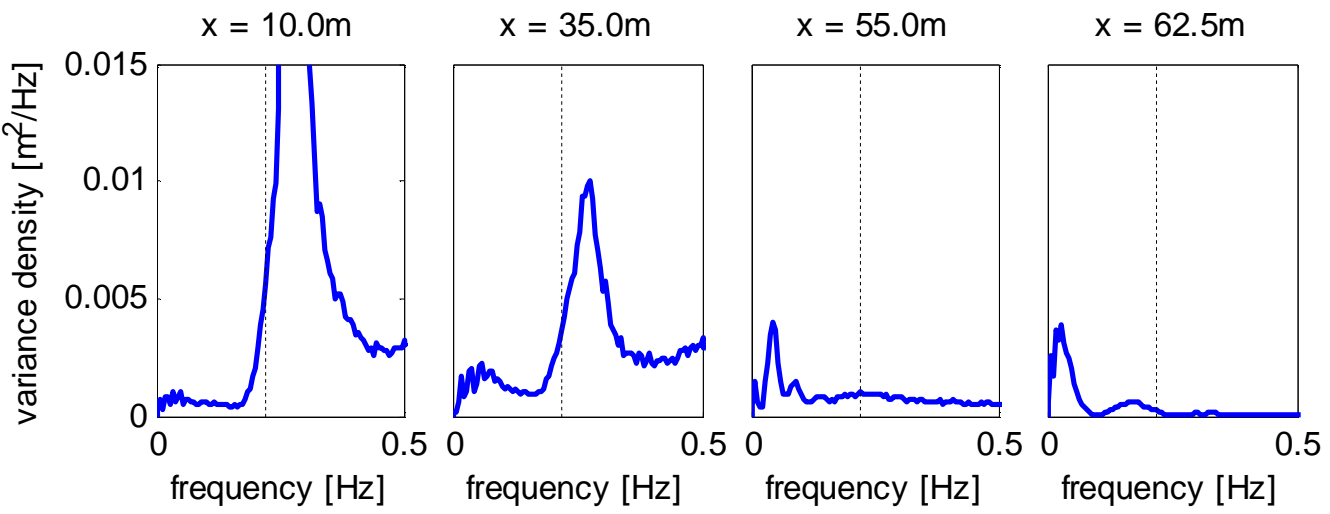

Figure 5 Measured spectrum transformation over wave flume. The dashed line indicates the split value between low- and high-frequency wave energy.

The morphological response of the barrier island in the physical model clearly shows three stages of overwash (Figure 6). These stages correspond to the stages discerned by [Steetzel and Visser, 1992]. In the physical model tests, the three stages of overwash are preceded by a stage of erosion. In order to force the stage of erosion to continue into the stage of overwash, the boundary conditions are changed gradually. In different experiments, either the water level, the wave height or the wave period is increased.

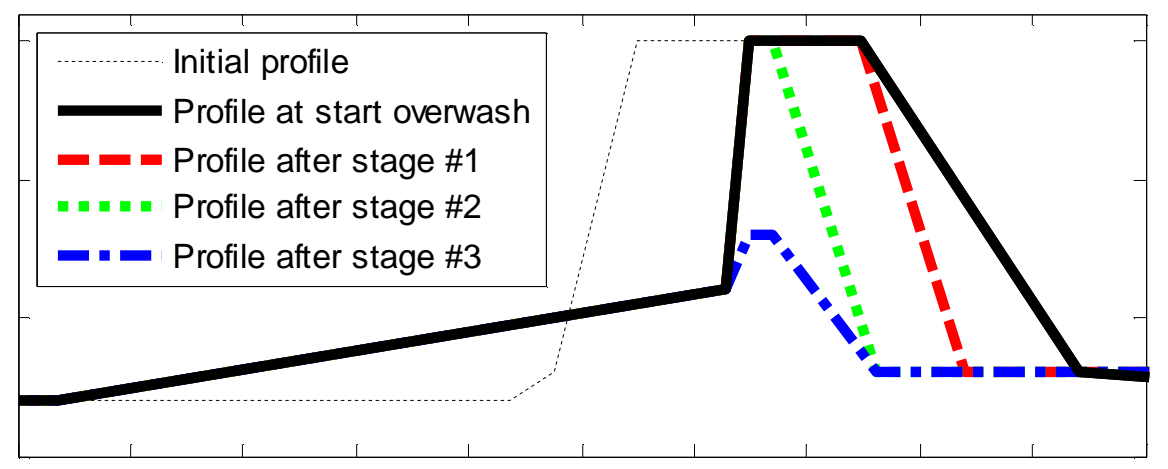

Figure 6 Stages of overwash erosion

In the physical model experiments, two other changes in morphology worth mentioning are observed as well: formation of ripples on the foreshore and erosion of the seaward boundary of the foreshore. The ripples had a length of about $5 \mathrm{~cm}$ and a height of about $0.5 \mathrm{~cm}$. The erosion of the shallow foreshore was considerable leading to a gradual decrease of the foreshore during the experiments.

\section{XBEACH MODEL SET-UP}

$\mathrm{XBeach}$ is a two-dimensional, numerical, wave group resolving, morphological model that supports slumping of dune faces and provides a fluent transition between the different impact regimes from collision to overwash and inundation [Roelvink et al., 2009]. XBeach is therefore particularly suitable for describing the morphological response of barrier islands on storm surges.

In this research, the physical model experiments are reproduced using a one-dimensional XBeach model with varying grid size. In this model, the original bathymetry, at the scale used in the physical facilities, is used. The same holds for the boundary conditions imposed to the model. The boundary conditions are imposed as parametric descriptions of the used wave spectra. These descriptions are equal to the spectral definitions sent to the wave generator in the physical model experiments. The exact realization of the wave signal, however, was therefore different.

All numerical model experiments are run using mainly default settings. However, a few deviations appeared to be necessary to obtain satisfying results. These are explained in the following sections. 


\section{Short wave breaking}

Five short-wave breaking formulae are currently implemented in XBeach: Baldock [Baldock et al., 1998], the original and adapted version of Roelvink [Roelvink, 1993], Roelvink-Daly [Daly et al., 2011] and Janssen-Battjes [Janssen and Battjes, 2007].

All formulations implemented a parameter $\gamma$ to calibrate the rate of breaking. In the Baldock and Janssen-Battjes approaches $\gamma$ is a breaker parameter, since they use the formulation of [Battjes and Janssen, 1978] to compute the maximum wave height:

$$
H_{b}=\frac{0.88}{k} \tanh \left(\frac{\gamma}{0.88} k h\right)
$$

For deep water $(k h \rightarrow \infty)$, the formulation limits to $0.88 / k$ and is related to wave steepness. For shallow water ( $k h \rightarrow 0$ ), the formulation limits to $\gamma h$ and is related to water depth. The value of $\gamma$ is assumed to be constant in these formulations. An often used estimation, based on several laboratory and field experiments, is given by [Battjes and Stive, 1985]:

$$
\gamma=0.5+0.4 \tanh \left(33 s_{0}\right)
$$

$\mathrm{s}_{0}$ is the deep water wave steepness. [Ruessink et al., 2003] used an inverse modeling approach to determine the value of $\gamma$ in several field experiments. It was concluded that $\gamma$ was not constant, but varied spatially. An alternative formulation was suggested that is dependent on the water depth and wave number (Figure 7):

$$
\gamma=0.76 k h+0.29
$$
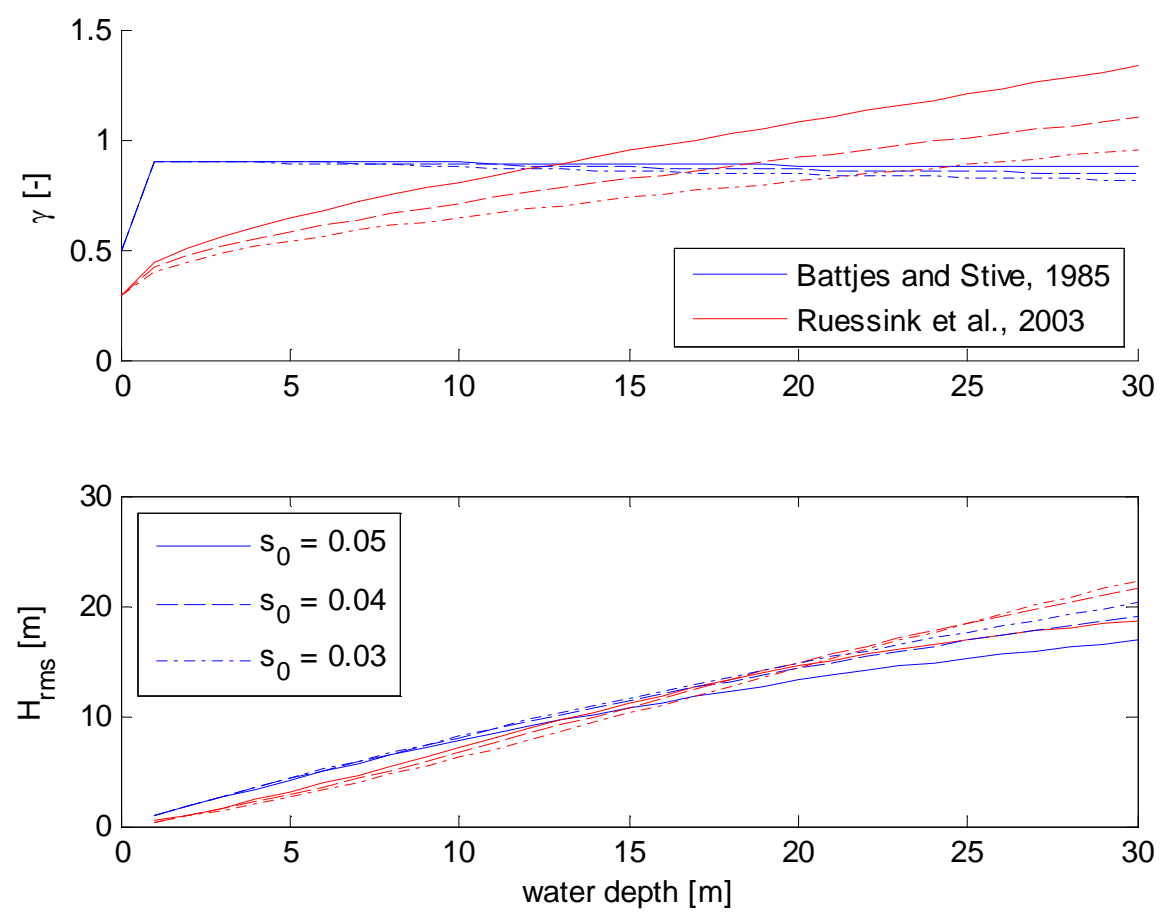

Figure 7 Comparison $y$ and corresponding maximum wave height as function of the water depth for offshore varying wave steepness according to [Battjes and Stive, 1985] and [Ruessink et al., 2003]. The wave height is $7 \mathrm{~m}$ in all cases.

Since the physical model experiments are performed with random waves, the adapted Roelvink formulation is used in the numerical model experiments discussed. The Roelvink approach computes the fraction of breaking waves $\mathrm{Q}_{\mathrm{b}}$ using the following formulation:

$$
Q_{b}=1-e^{-\left(\frac{H_{r m s}}{\gamma \cdot h}\right)^{n}}
$$

Although the formulation contains a $\gamma$ as well, this $\gamma$ is not a real breaker parameter, but a generic calibration coefficient. Therefore, the values are not equal to the values used in the Baldock and 
Janssen-Battjes approach. The use of the parameter for calibration purposes is nevertheless similar and a dependency on the local water depth and wave number can also be expected in the Roelvink formulations.

After the numerical model was calibrated using the reference profile (Figure 4), the profile with the shallow foreshore (Figure 2) indeed showed overestimations in the simulated wave height. The overestimations were concentrated mainly on the shallow foreshore. Therefore, $\gamma$ was decreased from the default value of 0.55 to 0.45 for the experiments with a shallow foreshore.

\section{Equilibrium sediment concentration}

Two equilibrium sediment concentration formulae are currently implemented in XBeach: Soulsby-Van Rijn [Soulsby, 1997] and Van Thiel-Van Rijn [Van Rijn, 2007]. The latter is used in the numerical model experiments and is described by:

$$
c_{e q}=\frac{A_{s b}}{h}\left(\sqrt{\left(u^{E}\right)^{2}+0.64 u_{r m s, 2}^{2}}-u_{c r}\right)^{1.5}+\frac{A_{s s}}{h}\left(\sqrt{\left(u^{E}\right)^{2}+0.64 u_{r m s, 2}^{2}}-u_{c r}\right)^{2.4}
$$

In the formulation, $\mathrm{u}_{\mathrm{rms}, 2}$ is the near-bed short-wave orbital velocity obtained from the wave-group varying wave energy including wave breaking induced turbulence:

$$
u_{r m s, 2}^{2}=u_{r m s}^{2}+1.45 k_{b}
$$

In this formulation, $u_{\mathrm{rms}}$ is the instantaneous short-wave orbital velocity. $\mathrm{k}_{\mathrm{b}}$ accounts for the breaking induced turbulence. Breaking induced turbulence is expected to have a minor influence on the sediment transport and erosion processes on the scale of the physical model experiments. The influence in the numerical experiments, however, appeared to be rather large. Therefore, $\mathrm{k}_{\mathrm{b}}$ is set to zero for all numerical experiments.

\section{Courant-Friedrichs-Lewy condition for diffusion}

The numerical time step in XBeach is automatically computed based on Courant-Friedrichs-Lewy (CFL) conditions. The automated time step computation ensures numerical stability. Nevertheless, initially the model showed numerical instabilities around the waterline. The diffusion coefficient in the sediment advection-diffusion equation appeared to be the cause of the instabilities, resulting in unrealistic large sediment concentrations and deformations of the profile. An extra CFL condition is implemented to prevent these instabilities according to [Vreugdenhil, 1989]:

$$
\Delta t=\frac{\Delta x^{2}}{2 D}
$$

$\mathrm{D}$ is the diffusion coefficient. The formulation is currently only implemented for one-dimensional models.

\section{XBEACH MODEL RESULTS}

The XBeach results are compared to the measurements on three levels: parametric and spectral hydrodynamics and morphodynamics. The results are presented for the erosion and overwash experiments separately.

\section{Erosion experiments}

The comparison shows that the hydrodynamics are well predicted by XBeach. Over the shallow foreshore, the high-frequency wave height is somewhat overpredicted by XBeach, despite of the changed value for $\gamma$. The low-frequency wave height is especially near the dune front, where it is most relevant, well predicted (Figure 8). Offshore, the simulated high- and low-frequency wave heights are a bit off. However, the measurements by the wave height meter in the most offshore position might be inaccurate, due to calibration problems experienced during the physical model experiments.

Figure 9 shows the spectrum transformation over the flume. In this figure, the full measured spectrum is shown and the low-frequency part of the simulated spectrum, since the high-frequency waves are not resolved by XBeach. Again, the offshore location shows some deviation with the measurements, but the spectra at the other locations show good agreement. 


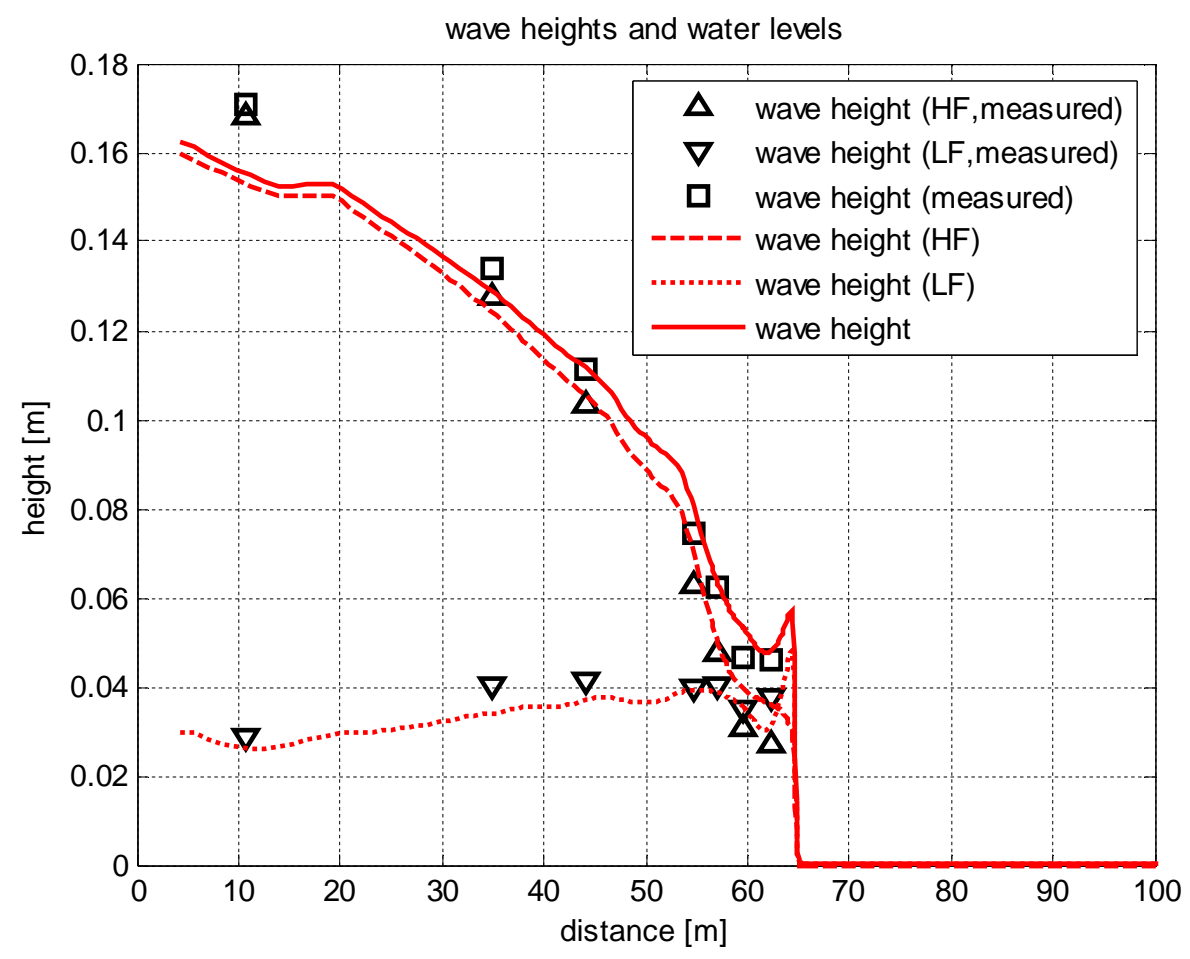

Figure 8 Measured and simulated high- and low-frequency wave height in experiment B2a
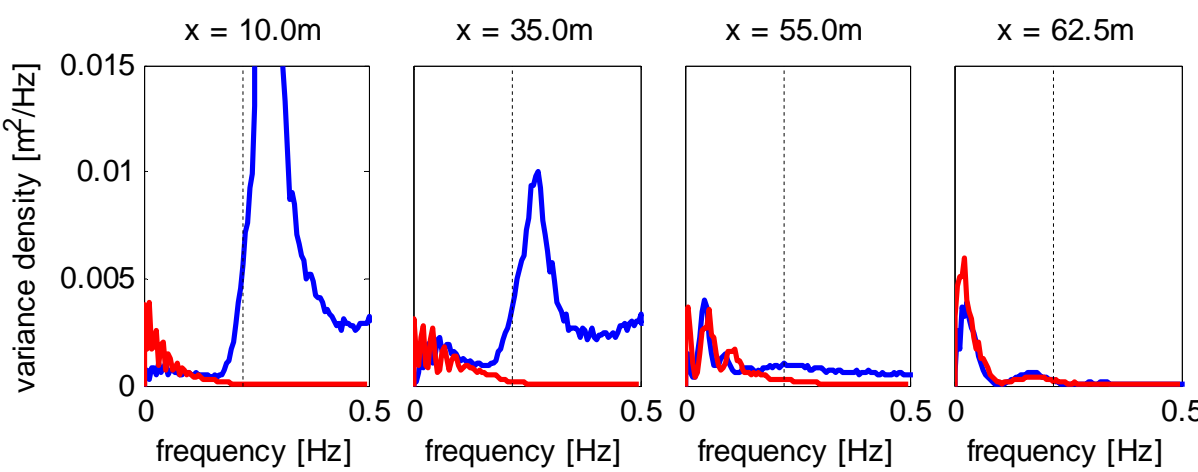

Figure 9 Measured full and simulated low-frequency wave spectrum transformation over wave flume during experiment B2a

Figure 10 shows the profile development in time, corresponding to the hydrodynamics just discussed. The retreat of the dune face shows a fairly good agreement with the measurements. However, the corresponding erosion volumes above surge level seem to be a bit overpredicted (Figure 12). This can be explained partly by the differences in the slope of the dune face. Where the simulated dune face shows a slope of approximately 1:1, which is a model setting, the measurements show an almost vertical dune face. During the physical model experiments, negative slopes or dune faces leaning over are observed due to some cohesive effects. The wheel profiler used to measure the profile development ran from the top down. Any dune faces leaning over are therefore not measured (except by video, see Figure 11). The cohesive effects and consequently the dune faces leaning over might very well explain a $10 \%$ difference in dune erosion volume. It also explains the differences in the slope of the dune face. However, the steep slopes observed in the measurements are also considered to be a scale effect related to cohesion. This is not reproduced by XBeach. XBeach will therefore always compute more gentle slopes on this scale. 


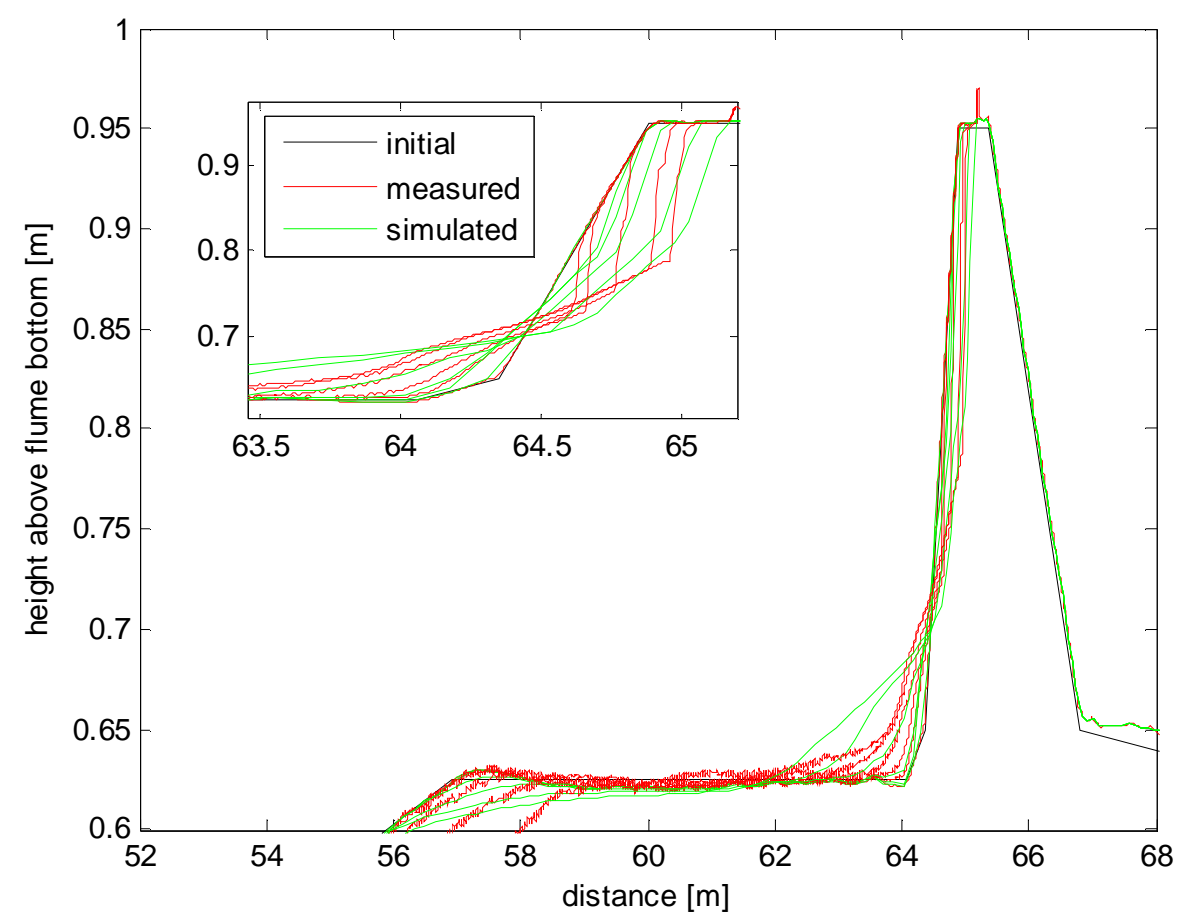

Figure 10 Profile development in time during experiment B2a. This inset is a magnification of the profile development at the dune face.
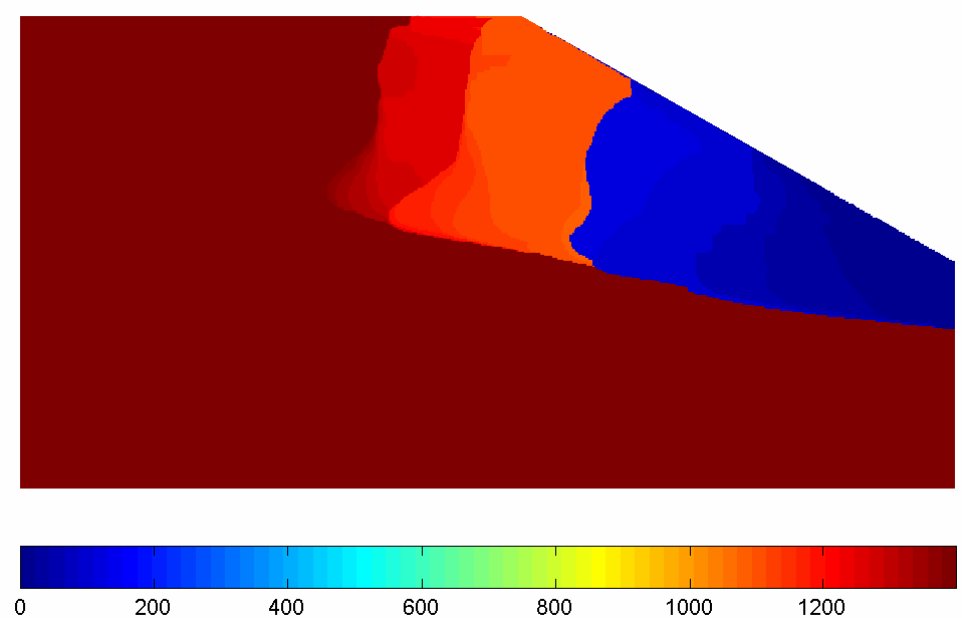

Figure 11 Dune face development measured by side-view camera during experiment B2a showing a dune face leaning over. The color scale is time in seconds.

The offshore border of the shallow foreshore shifts towards the dune, decreasing the length of the foreshore (Figure 10). Erosion of the foreshore is also observed in the numerical model. The amount of erosion and the shape of the eroded profile are different. Where in the measurements the transition between the horizontal foreshore and the more offshore part of the profile shifts without many changes in shape, the simulation shows more gradual erosion in time and space of the foreshore. 

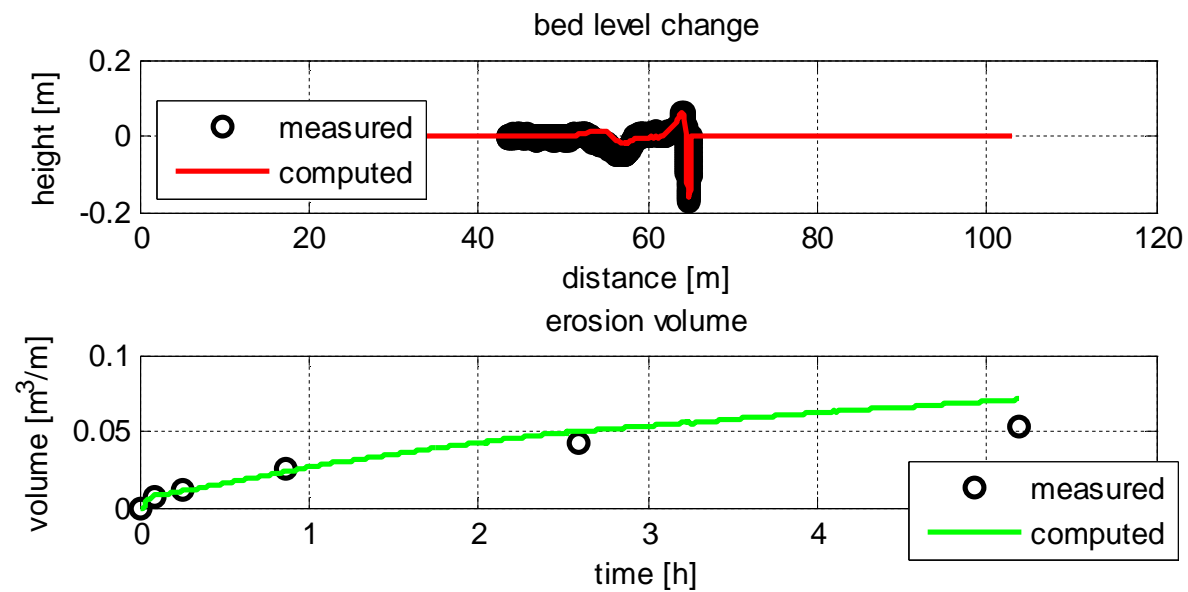

retreat distance

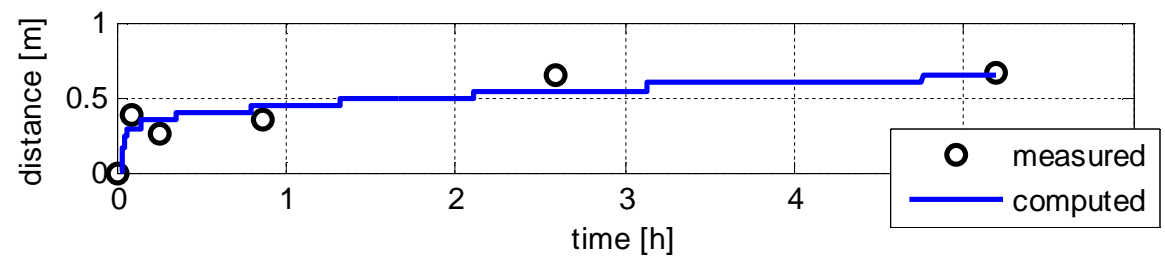

Figure 12 Measured and computed bed level change, erosion volume and retreat distance during experiment B2a

In the erosion experiments other than the $\mathrm{B} 2 \mathrm{a}$ experiment, the imposed wave conditions are different. With respect to experiment A2a, the wave height is increased in experiment B1a, while the wave length is increased in experiment B2a. Offshore, the difference in wave height is clearly visible (Figure 13). In experiment B1a, the high waves quickly dissipate on the shallow foreshore, resulting in a wave height near the dune toe similar to the A2a experiment. Part of the dissipated short wave energy is, however, shifted to the lower frequencies. The long wave energy at the dune toe is therefore higher than in experiment A2a and so is the erosion volume (Figure 14).

In contrast, the longer waves in experiment $\mathrm{B} 2 \mathrm{a}$ tend to dissipate less on the shallow foreshore. Also, the long wave energy is increased with respect to experiment A2a. The short wave energy is carried over the shallow foreshore by these long waves. This also results in increased wave energy at the dune toe and therefore increased dune erosion volumes.

The wave transformations are simulated well by XBeach considering the comments made regarding the B2a experiment. Especially, the relative change in wave height transformations in the different experiments is well predicted. The short wave heights correspond fair to the measurements. The low frequency wave heights offshore are a bit underpredicted. It should be noted that better results are obtained using a slightly different analysis method, but the default is used. 


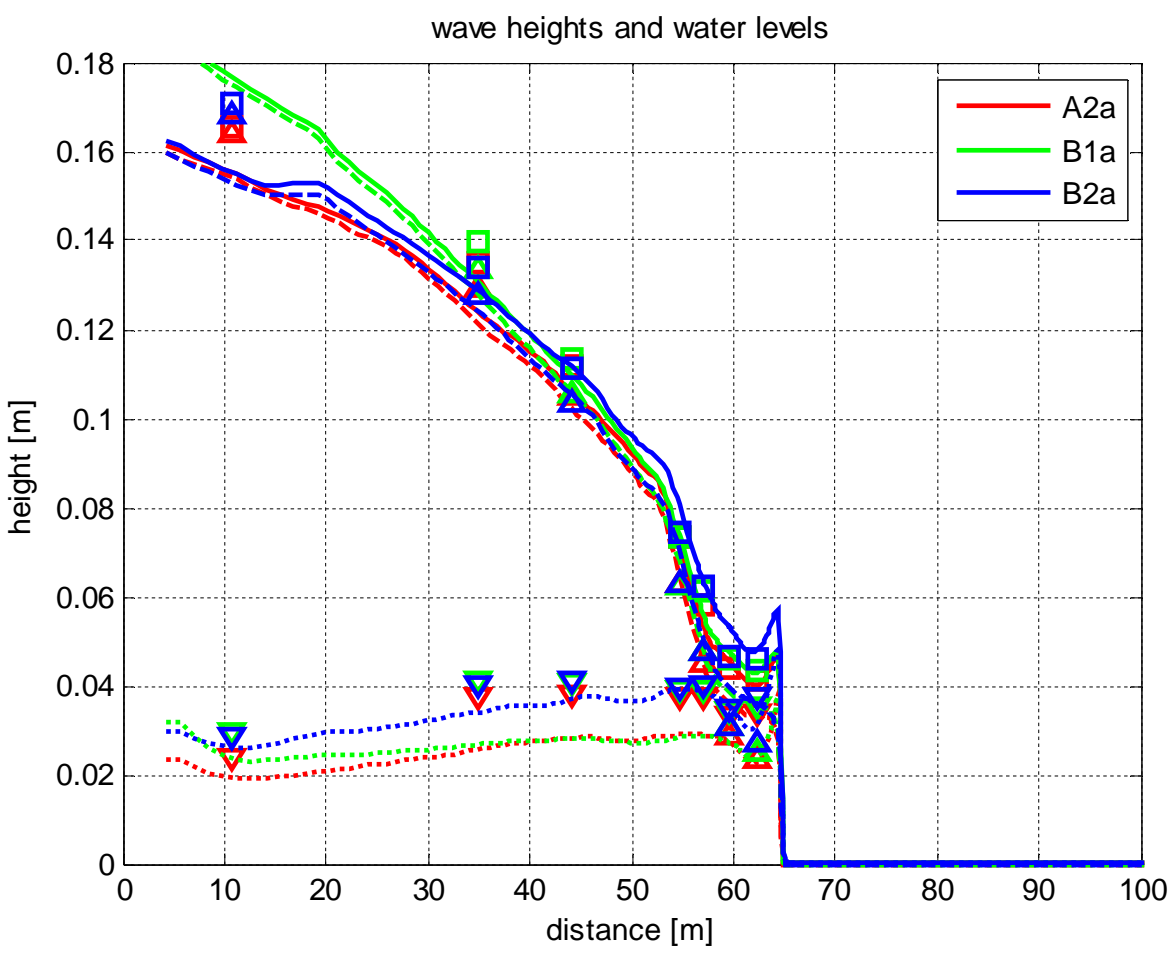

Figure 13 Comparison wave height transformations for experiments A2a, B1a (increased wave height) and B2a (increased wave period)

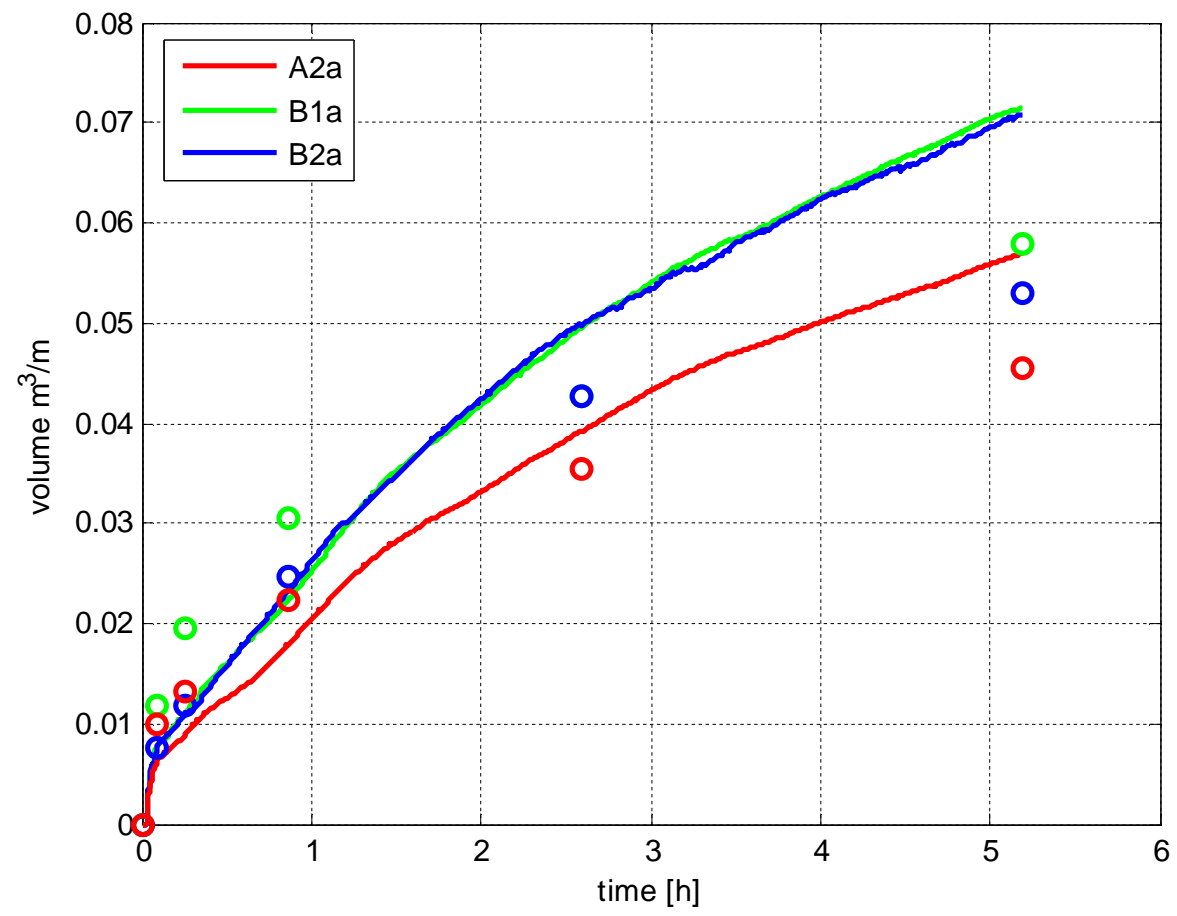

Figure 14 Comparison erosion volumes for experiments A2a, B1a (increased wave height) and B2a (increased wave period)

The erosion volumes are, again, predicted well relative to each other. With respect to the measurements there is some deviation at the end of the experiments. The remarks considering the possible negative slopes of the observed dune faces may again explain these differences of about $20 \%$. 


\section{Overwash experiments}

The differences in erosion volumes and profiles between the measurements and simulations are, as discussed in the previous section, expected to be partly related to the measurement techniques and cohesive effects. Therefore, the final profile of the erosion simulation is used as starting profile of the overwash simulation and not the measured profile.

Although a few waves overtopped in the XBeach simulation of experiment B2d, no breakthrough occurs in any of the simulations (Figure 15). In the physical model experiments, a breakthrough was forced in each experiment. As for now, the exact reason of this major difference is unknown, but two observations may be important here:

- The low frequency wave energy is under-predicted in XBeach (Figure 13), while this is the main driving force in overtopping in XBeach.

- Observations in the physical model experiments showed that the overtopping of waves and the erosion of the rear-side slope was highly three-dimensional (Figure 1) and initiated by small longshore perturbations in the bathymetry. Both effects are not simulated in the onedimensional XBeach model.

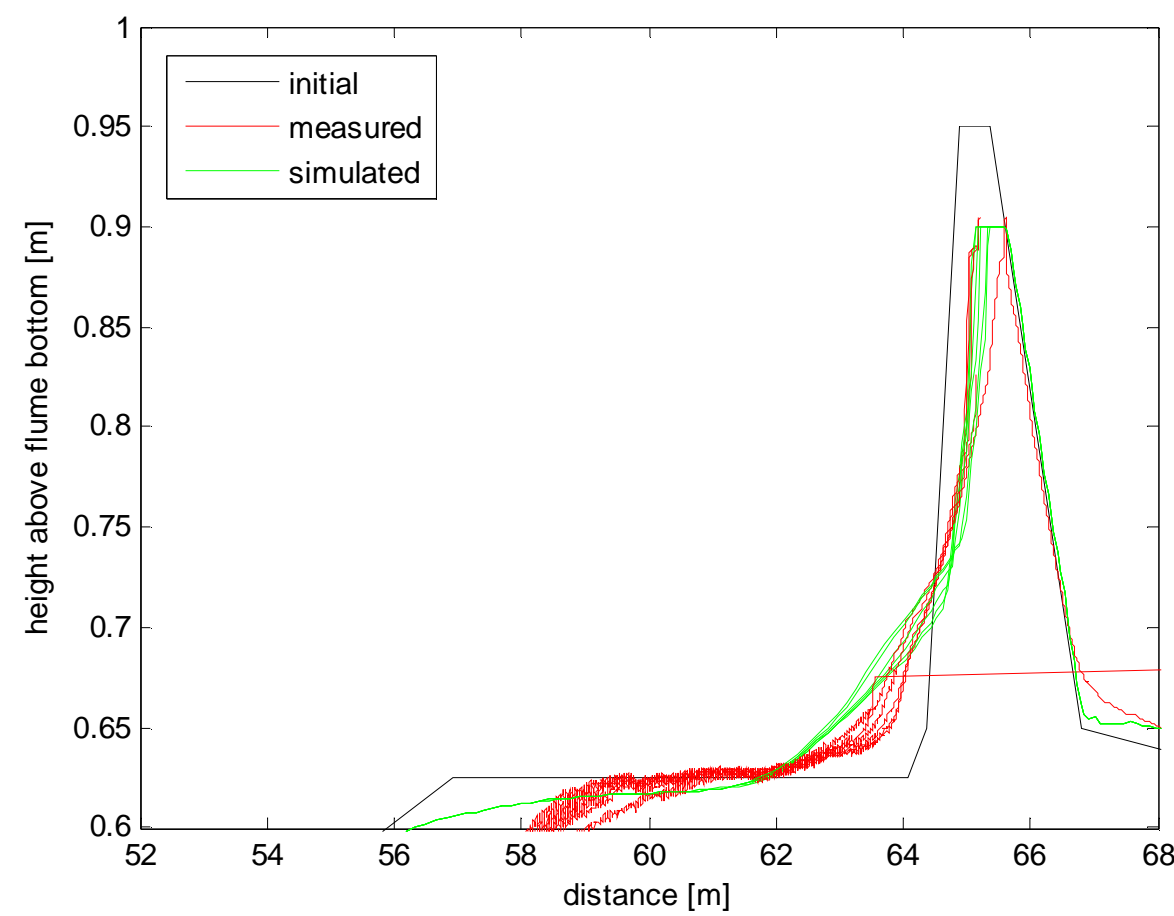

Figure 15 Profile development in time during experiment B2d

Further calibration of the low frequency wave heights is needed to simulate the overwash experiments well. Preliminary simulations show that altering the value of the complex breaker parameter can steer the amount of overtopping and thus force a breakthrough. More precise calibration is needed to find an optimal setting for both the erosion and overwash experiments.

The three-dimensional effects and the effects of small longshore perturbations in the bathymetry can be investigated using a high resolution two-dimensional XBeach model. The results of this model set-up are not yet analyzed and therefore not discussed here.

\section{CONCLUSIONS}

XBeach simulates the main characteristics in hydro- and morphodynamics at profiles with shallow foreshores, as found on barrier islands in both the Netherlands and the United States, well. However, the absolute results of especially the overwash experiments still do not agree with the measurements. It is expected that several difficulties related to the small scale of the physical model experiments play a role here:

- Cohesive effects and dune faces leaning over disturb the erosion volume and profile measurements. 
- The very shallow water at the shallow foreshore (order of centimeters) and the relatively large ripples observed disturb the hydrodynamic measurements.

- The initiation of overwash and the erosion of the rear-side slope was related to small perturbations in the bathymetry, which are not present in the XBeach model.

Nevertheless, calibration of the XBeach model seems to be necessary for shallow profiles. On this small scale, calibration appears to be a delicate job. Especially the calibration of the wave characteristics on the shallow foreshore, related to the morphodynamics is far from trivial.

At the same time, not all possibilities for calibration are jet exhausted. Also, it is expected that on larger scales, the need for calibration decreases since the observed disturbances (ripples, water depths, bathymetry, etc.) are relatively smaller. The three-dimensional effects are not yet investigated, but are likely to play a role on all scales.

It is recommended to run the XBeach model on prototype scale and compare the erosion volumes observed with those in the physical model experiments. This requires the use of scale relations [Vellinga, 1986]. It is also recommended to set up a small scale, high resolution, two-dimensional model for the overwash experiments. This model can be equipped with small perturbations in the bathymetry, if necessary. It is expected that the highly dynamic overwash experiments can better be investigated using such model.

Of course, it would be very useful to obtain similar measurement results on larger scales to verify the assumption that the differences between the physical and numerical experiments are partly scalerelated.

\section{REFERENCES}

[Baldock et al., 1998]Baldock, T. E., Holmes, P., Bunker, S., and Van Weert, P. (1998). Crossshore hydrodynamics within an unsaturated surf zone. Coastal Engineering, 56:1133-1152.

[Battjes and Janssen, 1978]Battjes, J. A. and Janssen, J. P. F. M. (1978). Energy loss and set-up due to breaking of random waves. In Proceedings 16th International Conference on Coastal Engineering, pages 570-587, New York. ASCE.

[Battjes and Stive, 1985]Battjes, J. A. and Stive, M. J. F. (1985). Calibration and verification of a dissipation model for random breaking waves. Journal of Geophysical Research, 90:9159-9167.

[Daly et al., 2011]Daly, C., Roelvink, J. A., Van Dongeren, A. R., Van Thiel de Vries, J. S. M., and McCall, R. T. (2011). Validation of an advective-deterministic approach to short wave breaking in a surf-beat model. Coastal Engineering. In Press.

[Deltares, 2011]Deltares (2011). Dune erosion and overwash at wide beaches - part b: measurement results of experiments in the scheldt flume. Report 1202124-007-HYE-0005, Deltares.

[Janssen and Battjes, 2007] Janssen, T. T. and Battjes, J. A. (2007). A note on wave energy dissipation over steep beaches. Coastal Engineering, 45:711-716.

[McCall et al., 2011]McCall, R. T., Van Geer, P. F. C., and Hoonhout, B. M. (2011). Physical modeling of storm-induced erosion and overwash. In Proceedings 7th International Symposium on Coastal Engineering and Science of Coastal Sediment Processes, Miami, Florida.

[Roelvink, 1993]Roelvink, J. A. (1993). Dissipation in random wave groups incident on a beach. Coastal Engineering, 19:127-150.

[Roelvink et al., 2009] Roelvink, J. A., Reniers, A. J. H. M., Van Dongeren, A. R., Van Thiel de Vries, J. S. M., McCall, R. T., and Lescinski, J. M. (2009). Modelling storm impacts on beaches, dunes and barrier islands. Coastal Engineering, 56(11-12):1133-1152.

[Ruessink et al., 2003]Ruessink, B. G., Walstra, D. J. R., and Southgate, H. N. (2003). Calibration and verification of a parametric wave model on barred beaches. Coastal Engineering, 48:139149.

[Sallenger, 2000] Sallenger, A. H. (2000). Storm impact scale for barrier islands. Journal of Coastal Research, 16(3):860-895.

[Soulsby, 1997]Soulsby, R. L. (1997). Dynamics of Marine Sands. Thomas Telford, London. 
[Steetzel and Visser, 1992]Steetzel, H. J. and Visser, P. J. (1992). Profile development of dunes due to overflowprofile development of dunes due to overflow. In Proceedings 23rd Coastal Engineering Conference, pages 2669-2679. ASCE.

[Van Rijn, 2007]Van Rijn, L. C. (2007). Unified view of sediment transport by currents and waves, part i, ii, iii and iv. Journal of Hydraulic Engineering, 133:649-689 (part I \& II), 761-793 (part III \& IV).

[Van Thiel de Vries, 2009] Van Thiel de Vries, J. S. M. (2009). Dune erosion during storm surges. $\mathrm{PhD}$ thesis, Delft University of Technology.

[Vellinga, 1986]Vellinga, P. (1986). Beach and Dune Erosion during Storm Surges. PhD thesis, Delft University of Technology.

[Vreugdenhil, 1989]Vreugdenhil, C. B. (1989). Computational Hydraulics - An Introduction. Springer-Verlag, Berlin. 